\title{
Scientific Basis of a Unique Formulation for Reducing Sunburn of Fruits
}

\author{
Larry E. Schrader \\ Washington State University Tree Fruit Research \& Extension Center, 1100 N. Western Avenue, \\ Wenatchee, WA 98801
}

Additional index words. apple (Malus domestica), sunburn browning and necrosis, RAYNOX ${ }^{\circledR}$, fruit surface temperature, solar radiation

\begin{abstract}
Sunburn, a major type of solar radiation injury, causes large economic losses of several fruits, vegetables, and ornamentals. Sunburn necrosis occurs in attached apple (Malus domestica Borkh.) when excess solar radiation is converted to heat energy and causes a high fruit surface temperature (FST). When the FST reaches $\approx 52^{\circ} \mathrm{C}$, thermal death of cells is induced and sunburn necrosis appears later. A second type of sunburn, sunburn browning, is caused by the combination of high FST (46 to $49^{\circ} \mathrm{C}$ ) and high solar radiation. Cell death is not induced, but several pigment changes occur and the apple peel typically turns yellow or brown. The objective of this study was to develop a unique technology for protection of apples from sunburn necrosis and sunburn browning. Natural waxes in the cuticle and pigments in the upper epidermis of apple, which reflect and absorb ultraviolet radiation, attenuate only part of the harmful ultraviolet radiation. I hypothesized that applying additional wax as a sprayable emulsion would augment natural waxes in the cuticle and that addition of reflective compounds to the wax emulsion would reduce the heat load on the fruit. Synthesis of a formulation of this composition would be unique for plants and would be akin to sunscreens used by humans that generally contain organic (chemical) compounds to absorb harmful ultraviolet radiation and inorganic (physical) compounds to scatter, block, and/or reflect solar radiation. Emulsified carnauba wax, a natural plant wax, decreased transmission of ultraviolet radiation; addition of emulsified, organically modified clay to the wax emulsion enhanced reflectivity. When combined into a sprayable formulation, the carnauba wax and organoclay emulsion was more effective in protecting apples from sunburn browning than from sunburn necrosis. Spraying the unique formulation on apple trees caused no phytotoxicity on either leaves or fruit and did not decrease leaf chlorophyll fluorescence or whole-tree gas exchange, indicating no effect on photosynthesis or transpiration of apple trees. The unique formulation is patented as a sunburn protectant for fruits and vegetables and is marketed in several countries as RAYNOX ${ }^{\circledR}$.
\end{abstract}

Sunburn, a result of high solar radiation that overwhelms natural protection systems, causes large economic losses in fruits and vegetables grown in arid and semiarid regions of the world. Sunburn damage to apples (Malus domestica Borkh.) has been exacerbated by the widespread adoption of highdensity plantings on size-controlling rootstocks. Young trees have open canopies and many of the fruit are fully exposed to sunlight for several hours daily. Hence, the incidence of sunburn can be high. In Washington State, cullage resulting from sunburn averages $\approx 10 \%$ each year for apple growers who do not use practices to protect fruit from sunburn. In some parts of the world (e.g., Chile, South Africa, and Australia), losses resulting from sunburn often exceed 10\% (Gindaba and Wand, 2005).

Symptoms of sunburn vary widely, from a whitened area on the fruit to areas that are yellow, brown, tan, or bronze; the most serious sunburn damage results in dark brown or black

Received for publication 23 Aug. 2010. Accepted for publication 14 Oct. 2010.

The financial support of the Washington Tree Fruit Research Commission (WTFRC) is gratefully acknowledged. The cooperation and assistance from WTFRC staff in spraying trees and evaluation of sunburn incidence are also acknowledged. I am grateful to Rudi Kammereck and William Duplaga for technical assistance and to Don Elfving, Eric Curry, Richard Baskin, and Cindy Kahn for thoughtful and helpful reviews of the manuscript. Mention of trade names of commercial products in HortScience is solely for the purpose of providing specific information and does not imply recommendation or endorsement by the American Society for Horticultural Science.

e-mailschrader@wsu.edu. areas that become necrotic. These symptoms actually represent three types of sunburn in apple, which have been identified and characterized (Schrader et al., 2004). Apparently, most investigators in the past did not perceive that more than one type of sunburn might exist and that the causes for each type of sunburn might also be different. Thus, it is difficult to ascertain which type of sunburn was described in many earlier publications. Further confusion developed because some studied sunburn of detached fruits without being cognizant that attached and detached fruit respond differently to high solar radiation and high temperature. For example, Rabinowitch et al. (1983) reported that detached cucumbers (Cucumis sativus L.) and peppers (Capsicum annuum L.) had significantly higher surface temperatures and more serious sunburn injury than attached fruit, but they continued to use detached fruit in subsequent studies (Rabinowitch et al., 1986). Although sunburn necrosis can be induced on detached fruit, attempts to induce sunburn browning symptoms similar to those observed under field conditions have been unsuccessful with detached apples, at several stages of development, in my laboratory and elsewhere (W.J. Steyn and Elmi Lötze, Dept. Hort. Sci., Stellenbosch Univ., Matieland, South Africa, personal communication).

High temperatures of air or of the fruit surface have been reported to cause sunburn. Serr and Foott (1963) found that $38^{\circ} \mathrm{C}$ was a critical air temperature for sunburn of walnut (Juglans regia L). Rabinowitch et al. (1986) reported air temperature thresholds from 38 to $40{ }^{\circ} \mathrm{C}$ and 40.5 to $42.5^{\circ} \mathrm{C}$ were essential for development of sunburn injury in cucumbers and peppers, respectively. Critical FST reported by others include: $50{ }^{\circ} \mathrm{C}$ for musk- melons (Cucumis melo L.) (Lipton and O'Grady, 1980); $42{ }^{\circ} \mathrm{C}$ for raspberry (Rubus idaeus L.) fruit (Renquist et al., 1989); and $40{ }^{\circ} \mathrm{C}$ for tomatoes (Lycopersicum esculentum L.) (Adegoroye and Joliffe, 1983; Rabinowitch et al., 1974). These authors did not indicate whether their critical air or FST values were for sunburn necrosis or sunburn browning. Schrader et al. (2001) reported minimum threshold FST of 46 to $49{ }^{\circ} \mathrm{C}$ for sunburn browning and $52{ }^{\circ} \mathrm{C}$ for sunburn necrosis of attached apples. The minimum FST for sunburn browning varied with cultivar.

Other authors [e.g., Parchomchuk and Meheriuk (1996) and Racskó et al. (2005)] reported that solar injury of apples results from tissue damage caused by radiant heating of the fruit surface when directly exposed to sunlight but listed no minimum FST. Similarly, Gindaba and Wand (2008) reported that high solar radiation during the summer results in excessive light and heat load on apple fruit that result in fruit skin browning or death of epidermal cells in the skin.

Ultraviolet radiation has been implicated in several papers as a cause of sunburn. Barber and Sharpe (1971) reported that ultraviolet radiation sunscald occurs on fruits grown at high altitudes. Kossuth and Biggs (1978) reported that ultraviolet radiation causes sunburn in blueberries (Vaccinium corymbosum L.). Lipton and O'Grady (1980) varied the ultraviolet flux in the field by covering 'Crenshaw' muskmelons with various plastic films; they demonstrated that solar injury developed only if both ultraviolet flux and temperature were above certain minimum levels. Renquist et al. (1987) reported that both high FST and ultraviolet irradiation were required for sunburn of raspberries in the field. Renquist et al. 
(1989) held detached raspberries at $42{ }^{\circ} \mathrm{C}$ or higher in the laboratory and needed 4 or more hours of ultraviolet radiation to induce sunburn. Yuri et al. (2000) concluded that temperature had more effect than did ultraviolet radiation on the appearance of sunscald on apples.

With apples, Schrader et al. (2001) were the first to identify and characterize two distinct types of sunburn induced in fruit attached to trees. The first type, sunburn necrosis, was induced after the FST of apples reached $52 \pm$ $1{ }^{\circ} \mathrm{C}$ for at least $10 \mathrm{~min}$ and was the result of heat-induced cell death. Direct sunlight was not required other than as a heat source. Cell membranes were damaged and leaked cellular contents; the sunburned area became dark brown or black (i.e., necrotic) a few days later. The second type, sunburn browning, occurred on attached apples that were previously exposed to full sunlight (i.e., acclimated to high solar radiation) and was induced under high solar radiation when the apple FST reached a certain minimum temperature. This threshold or minimum FST varied with cultivar from 46 to $49{ }^{\circ} \mathrm{C}$ under full sunlight. When sunlight was excluded from attached apples that were heated to the threshold FST, sunburn browning did not occur. Thus, both high FST and high solar radiation were required for induction of sunburn browning. In contrast to sunburn necrosis, cell membranes remained intact and thermal death of cells did not occur at the threshold FST required for sunburn browning (Schrader et al., 2001, 2003).

In 1997, no commercial product existed for effectively protecting apple fruit from sunburn damage. Sibbett et al. (1991) applied a commercial whitener (Sunguard), which was developed for walnuts, to 'Granny Smith' apples in California and concluded that apples could not be protected from sunburn by up to four topical applications of this particular whitening agent alone. Some Washington apple growers were using overhead evaporative cooling, shadecloth, or bagging of individual apples to reduce sunburn in their orchards, but each of these options was costly and had limitations.

Because effective sunburn protectants were not available commercially for apples, studies were initiated in my laboratory in 1997 to invent a sprayable formulation that would decrease sunburn in apples. Knowledge that high solar radiation, accompanied by high air temperatures, causes sunburn and that a reflective agent alone might not provide satisfactory control led to the hypothesis that a formulation comprised of a lipophilic wax emulsion containing some reflective materials would reduce damaging solar radiation and decrease FST of apples. The wax emulsion needed the capacity to absorb and disperse the reflective materials. It was intended to enhance the properties of the natural wax layer that exists on the surface of all fruits and vegetables and to allow passage of some ultraviolet and most visible solar radiation, which are required for color formation.

The major goal of this study was to invent a sprayable formulation that would bind with natural cuticle waxes and decrease sunburn in apples. The first objective was to identify ingredients that, in combination, would absorb or filter damaging solar radiation and increase reflectivity to reduce FST of fruit but not interfere with photosynthesis or transpiration. The second objective was to investigate the unique formulation's efficacy in protecting apples from sunburn damage. Third, physiological processes of leaves and fruit to which the unique formulation was applied were investigated to ascertain whether the formulation interfered with any of these processes.

\section{MATERIALS AND METHODS}

Synthesis of various formulations. The wax emulsion (wax matrix) was synthesized by melting and emulsifying wax with suitable emulsifiers. The preferred wax was carnauba wax, a natural wax from certain palm trees; reasons for its selection are discussed later. Both an anionic lipophilic emulsifier (e.g., oleic acid) and an ionic hydrophilic emulsifier (e.g., morpholine) were mixed with the wax in an amount sufficient to emulsify the edible waxes.

The wax matrix plus clay formulation was produced by combining a wax emulsion and a separate clay emulsion. The preferred clay is a thixotropic, smectic clay material that is chemically altered to render its surface lipophilic. Thixotropic clays in their original form are typically hydrophilic. To increase the ability of the unique formulation to adhere to the lipophilic surface of fruit, the clay is rendered lipophilic by chemical transformation of the clay with quaternary ammonium compounds in which the ligands consist entirely of aliphatic long-chain hydrocarbons or of a mixture of aliphatic and aromatic hydrocarbon residues. This reaction converts the hydrophilic clay into a hydrophobic and lipophilic material that is capable of molecularly dispersing oils, waxes, and other lipid-like materials, including organic solvents. A suitable organoclay is Thixogel MP 100 supplied by Süd-Chemie Rheologicals, a division of United Catalysts Inc., Louisville, KY.

The unique formulation, which later became RAYNOX ${ }^{\circledR}$, was synthesized after optimizing the ratio of carnauba wax to organoclay. A list of components suitable for the formulation was included in the composition patent (Kammereck and Schrader, 2005). The preferred composition contains carnauba wax, organoclay, morpholine, and oleic acid, but the final concentration of each component in the unique formulation is proprietary.

Transmission of solar radiation through formulations applied to quartz crucibles. Although solar radiation can be reflected, absorbed, or transmitted through leaves, solar radiation is not transmitted through fruit. Hence, radiation that reaches an unprotected fruit surface is absorbed and/or reflected. Absorbed radiation that is converted to heat energy increases the FST, whereas radiation reflected from the fruit, either naturally or as a result of applying a reflective substance, decreases the amount of solar radiation absorbed.

Although fruit cannot transmit radiation, a film of a formulation applied to fruit can reflect, absorb, and transmit radiation through the film. However, it is not possible to measure each of these parameters in situ on the fruit. Hence, matching 100-mL quartz crucibles were used to simulate apples. Quartz is required for studies of ultraviolet light transmission as standard glass contains impurities (i.e., various metal oxides) that absorb or disperse most or all ultraviolet-B radiation (Duarte et al., 2009). Quartz is pure $\mathrm{SiO}_{2}$ and transmits ultraviolet-B (Malitson, 1965).

To determine the percentage of radiation transmitted through the film provided by the sprayable formulations, quartz crucibles were sprayed with selected formulations and mounted on a special stand that permitted leveling of the crucible and the specific calibrated sensor to be used to measure transmission through each crucible in a similar position. Calibrated ultraviolet-A, ultraviolet-B, photosynthetically active radiation $(P A R)$, and near-infrared sensors were used for instantaneous measurements of transmission through the crucibles. The ultraviolet-B (PMA 2101) (280 to $320 \mathrm{~nm}$ ), ultraviolet-A (PMA 2110) (320 to $400 \mathrm{~nm}$ ), and infrared (GDA-U) (800 to $1800 \mathrm{~nm})$ sensors were used with a PMA 2100 Personal Measurement Assistant Meter and Datalogger (Solar Light Co. Inc., Philadelphia, PA). The quantum sensor (Model LI-190SA) (400 to $700 \mathrm{~nm}$ ) was used with the LI-COR LI-250 light meter (LI-COR, Inc., Lincoln, NE) for visible range radiation $(P A R)$. Each crucible was mounted on the stand and placed over each individual sensor separately. Measurements were taken under full sunlight near solar noon on clear days in mid-June (i.e., near the longest days of the year when solar radiation is maximal). At least three crucibles per treatment were used each time the experiment was conducted. The radiation that was not transmitted through the crucible was considered to be reflected and/or absorbed by the formulation sprayed on the crucible.

Reflectance of formulations containing different concentrations of smectic clay applied to quartz crucibles. The same crucibles used for transmission studies with various formulations were used for measuring reflectance. Results were more consistent with crucibles than with apples, because pigment composition of different apples varied and affected absorbance and reflectance measurements. A portable reflectometer (UniSpec ${ }^{\text {TM }}$ Spectral Analysis System; PPS Systems, Amesbury, MA) with an internal halogen light source measured reflectance near solar noon for the spectra between 305 and $1100 \mathrm{~nm}$. The fiberoptic probe of the reflectometer was mounted $5 \mathrm{~mm}$ from the surface of each crucible at an angle of $30^{\circ}$ from the vertical. The probe was positioned, using a compass, so it pointed due north to avoid casting a shadow on the south exposure of the crucible. The auto-scan feature on the instrument obtained and averaged 100 scans per crucible. Crucibles were coated with several variations of the unique formulation (i.e., clay was varied from $0 \%$ to $7 \%$ $\mathrm{w} / \mathrm{v}$ in the wax matrix), and reflectance was determined to ascertain the effect of increasing clay concentration in the formulation. 
Incidence of sunburn necrosis and sunburn browning of apples with wax matrix alone versus matrix plus clay. Sunburn protection efficacy of the formulation (containing wax matrix + organoclay described previously) was compared with wax matrix alone and untreated controls to establish whether incorporating reflective clay into the wax matrix was beneficial in decreasing fruit sunburn on 10-year-old 'Jonagold'/M.7 in 1997 and 7year-old 'Fuji'/M.26 trees in 1998. The formulations were diluted to $12.5 \%(\mathrm{v} / \mathrm{v})$ with water and applied to single-tree plots with a handgun sprayer at $\approx 1.0 \mathrm{MPa}$ to near the point of drip, simulating a dilute spray of $\approx 2000$ $\mathrm{L} \cdot \mathrm{ha}^{-1}$. Treatments were applied three times during both fruit-growing seasons and replicated four times in a completely randomized design. Both sunburn necrosis and sunburn browning were evaluated twice each season on the dates specified in Table 1.

Efficacy tests of the unique formulation for decreasing incidence of sunburn necrosis and sunburn browning in three apple cultivars. Based on studies described in the preceding section, the composition of the unique formulation was established. It was diluted to $12.5 \%(\mathrm{v} / \mathrm{v})$ with water and applied to single-tree plots replicated 10 times in a completely randomized design. All treatments were applied with a handgun sprayer at $\approx 1.0 \mathrm{MPa}$ to near the point of drip, simulating a dilute spray of $\approx 2000 \mathrm{~L} \cdot \mathrm{ha}^{-1}$. The formulation was applied three times during the 1999 fruit-growing season to 'Jonagold' and 'Cameo' on 7 July, 4 Aug., and 1 Sept. For 'Fuji', a fourth application was made 29 Sept. The untreated control trees were sprayed with water on the same dates. The incidence of sunburn necrosis and sunburn browning in all treatments was evaluated on all fruit on each tree in the 'Jonagold' and 'Cameo' experiments, but fruit on only two branches of 'Fuji' trees were evaluated, because they were much larger than the 'Jonagold' and 'Cameo' trees. Five-year-old 'Jonagold'/M.7A trees were treated in the Clayton Orchard near Orondo, WA. 'Cameo'/M.26 trees in the Fleming Orchard near Orondo, WA, were 3 years old; as a result of smaller tree size, two trees were included in each replication. Nine-year-old 'Fuji'/MM.106 trees were treated in the Fugachee Orchards near Pateros, WA.

Effect of unique formulation on chlorophyll fluorescence to determine maximum quantum efficiency of photosystem II. An OS5-FL Modulated Chlorophyll Fluorometer (OptiSciences, Inc., Hudson, $\mathrm{NH}$ ) was used to determine "dark-adapted" $F_{\mathrm{v}} / F_{\mathrm{m}} . \mathrm{F}_{\mathrm{v}} / \mathrm{F}_{\mathrm{m}}=\mathrm{F}_{\mathrm{m}}$ $-F_{o} / F_{m}$ where $F_{o}$ and $F_{m}$ are the minimal and maximal fluorescence yield of a dark-adapted leaf. Fluorescence was determined on five attached leaves per replication of 4-year-old 'Fuji'/M.26 trees in the WSU Columbia View orchard north of Wenatchee, WA. Five singletree replications of each treatment were used, and leaves were dark-adapted for 5 min before measurements. The unique formulation was applied as described previously to five trees, and five trees with no formulation served as the untreated controls. Chlorophyll fluorescence was measured $1 \mathrm{~d}$ after the formulation was applied.

Statistical analyses. Data expressed as percentages in Tables 1 and 2 were first transformed using the angular or inverse sine transformation method (Steel and Torrie, 1960) before performing a one-way analysis of variance (ANOVA). Means reported are backtransformed weighted means derived from the transformed data. Fluorescence data in Table 3 were evaluated using a one-way ANOVA.

\section{RESULTS}

Transmission of solar radiation through formulations applied to quartz crucibles. After two applications of the unique formulation (wax + clay) dried on the quartz crucibles, crucibles and sensors were transferred outside on a clear day at solar noon. Transmission of ultraviolet-B (280 to $320 \mathrm{~nm}$ ), ultraviolet-A ( 320 to $400 \mathrm{~nm}$ ), visible (400 to $700 \mathrm{~nm}$ ), and near-infrared (800 to $1800 \mathrm{~nm}$ ) radiation through the crucibles was decreased (Fig. 1). Transmission of ultraviolet-B radiation was decreased most (nearly $60 \%$ reduction), whereas ultraviolet-A transmission was reduced $\approx 40 \%$; transmission of visible and infrared radiation was reduced $\approx 10 \%$ each by two applications of the unique formulation.

Reflectance of formulations containing different concentrations of smectic clay applied to quartz crucibles. Reflectivity of the coated crucibles increased as the concentration of clay in the matrix was increased from $0 \%$ to $7 \%(\mathrm{w} / \mathrm{v}$ ) (Fig. 2). Reflectivity in the 700 - to $1100-\mathrm{nm}$ range was higher than in the visible region (400 to $700 \mathrm{~nm}$ ), and little reflectivity was observed below $400 \mathrm{~nm}$.

Incidence of sunburn necrosis and sunburn browning of apples with wax matrix alone versus matrix plus clay. During the first year of field testing, wax matrix only and matrix + organoclay significantly decreased sunburn necrosis of 'Jonagold' as compared with the untreated control on 19 Aug. (Table 1). With 'Fuji' in the second year, sunburn necrosis by 18 Aug. was also significantly decreased by matrix only and matrix + clay.

Incidence of sunburn browning on 19 Aug. in 'Jonagold' was significantly lower with the matrix + clay as compared with matrix alone or untreated control. With 'Fuji', sunburn browning was decreased significantly on 15 July and 18 Aug. when matrix alone or matrix + clay was applied and compared with untreated controls.

Table 1. Comparison of untreated control, carnauba wax matrix alone, and wax plus thixotropic clay on incidence of sunburn necrosis and sunburn browning of 'Jonagold' in 1997 and 'Fuji' apples in 1998.

\begin{tabular}{|c|c|c|c|}
\hline Cultivar and evaluation date & Control & Matrix only & Matrix + clay \\
\hline \multicolumn{4}{|c|}{ Incidence of sunburn necrosis (\%) } \\
\hline \multicolumn{4}{|l|}{ Jonagold } \\
\hline 29 July 1997 & $6.7 \mathrm{a}^{\mathrm{z}}$ & $9.7 \mathrm{a}$ & $5.0 \mathrm{a}$ \\
\hline 19 Aug. 1997 & $26.3 \mathrm{a}$ & $8.2 \mathrm{~b}$ & $9.1 \mathrm{~b}$ \\
\hline \multicolumn{4}{|l|}{ Fuji } \\
\hline 15 July 1998 & $3.3 \mathrm{a}$ & $3.3 \mathrm{a}$ & $6.7 \mathrm{a}$ \\
\hline 18 Aug. 1998 & $12.1 \mathrm{a}$ & $3.6 \mathrm{~b}$ & $6.7 \mathrm{~b}$ \\
\hline \multicolumn{4}{|c|}{ Incidence of sunburn browning (\%) } \\
\hline \multicolumn{4}{|l|}{ Jonagold } \\
\hline 29 July 1997 & $6.7 \mathrm{a}$ & $0 \mathrm{a}$ & $0 \mathrm{a}$ \\
\hline 19 Aug. 1997 & $17.5 \mathrm{a}$ & $16.4 \mathrm{a}$ & $3.6 \mathrm{~b}$ \\
\hline \multicolumn{4}{|l|}{ Fuji } \\
\hline 15 July 1998 & $33.3 \mathrm{a}$ & $16.7 \mathrm{~b}$ & $15.3 \mathrm{~b}$ \\
\hline 18 Aug. 1998 & $50.0 \mathrm{a}$ & $26.8 \mathrm{~b}$ & $20.0 \mathrm{~b}$ \\
\hline
\end{tabular}

${ }^{\mathrm{z}}$ Values within a row followed by the same letter are not significantly different from each other at $P<0.05$.

Table 2. Efficacy of the unique formulation in decreasing incidence of sunburn browning and sunburn necrosis in three cultivars in separate orchards during 1999.

\begin{tabular}{lccccc}
\hline & \multicolumn{2}{c}{ Sunburn browning } & & \multicolumn{2}{c}{ Sunburn necrosis } \\
\cline { 2 - 3 } \cline { 5 - 6 } Cultivar & $\begin{array}{c}\text { Untreated control } \\
(\%)\end{array}$ & $\begin{array}{c}\text { With formulation } \\
(\%)\end{array}$ & & $\begin{array}{c}\text { Untreated control } \\
(\%)\end{array}$ & $\begin{array}{c}\text { With formulation } \\
(\%)\end{array}$ \\
\hline Jonagold & $14.7 \mathrm{a}^{z}$ & $5.7 \mathrm{~b}$ & & $1.1 \mathrm{a}$ & $0.3 \mathrm{a}$ \\
Cameo & $13.4 \mathrm{a}$ & $4.7 \mathrm{~b}$ & & $0 \mathrm{a}$ & $1.9 \mathrm{a}$ \\
Fuji & $14.8 \mathrm{a}$ & $2.4 \mathrm{~b}$ & & $0 \mathrm{a}$ & $0 \mathrm{a}$ \\
\hline
\end{tabular}

${ }^{\mathrm{z}}$ Means within sunburn type and cultivar followed by the same letter are not significantly different $(P \leq$ $0.05)$ as determined by $\mathrm{F}$ test.

Table 3. Influence of unique formulation on chlorophyll fluorescence $\left(\mathrm{F}_{\mathrm{v}} / \mathrm{F}_{\mathrm{m}}\right)$ of 'Fuji' leaves (estimation of electron flow in photosystem II of photosynthesis) in each of five replications (five leaves per replication) ${ }^{\mathrm{z}}$

\begin{tabular}{llr}
\hline Treatment applied & \multicolumn{1}{c}{ Application dates } & $\mathrm{F}_{\mathrm{v}} / \mathrm{F}_{\mathrm{m}}$ \\
\hline Untreated & None & 0.80 \\
Unique formulation & 19 July, 27 July, 4 Aug. & 0.81 \\
Unique formulation & 12, 18, and 25 Aug. & 0.78 \\
Unique formulation & 19 and 27 July; 4, 12, 18, and 25 Aug. & 0.78 \\
\hline
\end{tabular}

zThe formulation was applied at different stages of development, and then Fv/Fm was measured on all treatments on 26 Aug. 


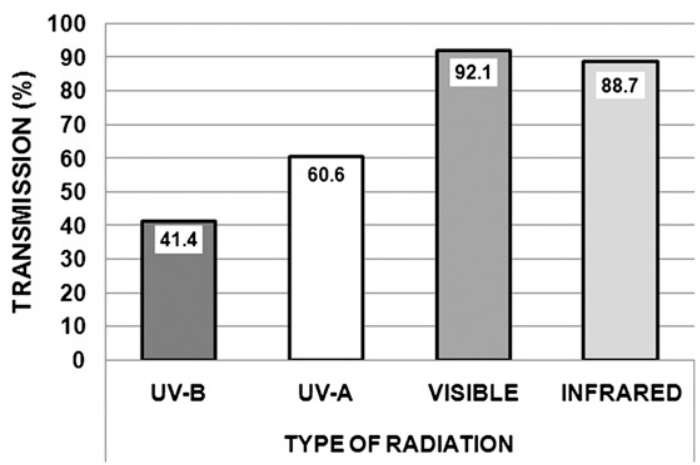

Fig. 1. Transmission of solar radiation of various wavelengths through quartz crucibles. One set of three crucibles was untreated, and another set of three was sprayed twice with the unique formulation at $12.5 \%(\mathrm{v} / \mathrm{v})$. The various calibrated sensors were placed on a level platform with the sensors placed under the crucible in a normal (perpendicular) position with respect to solar radiation. Measurements were taken near solar noon on a cloudless day. Percent transmission was calculated by comparing treated crucibles with untreated crucibles.

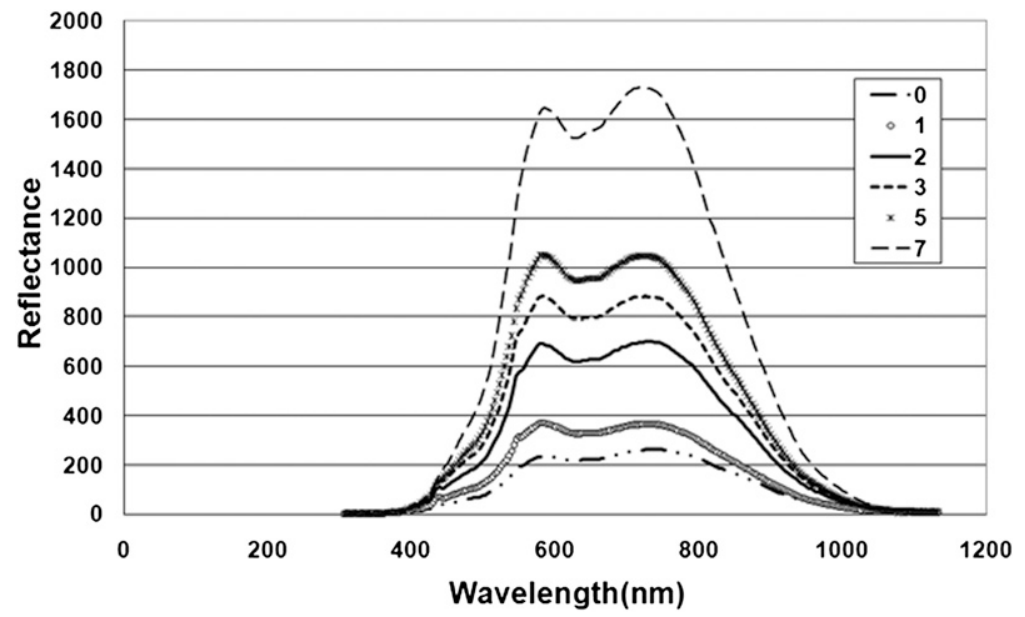

Fig. 2. Reflectance from quartz crucibles sprayed with the wax matrix containing various concentrations of clay. $0=$ no clay in wax matrix; $1,2,3,5$, and $7=1 \%(\mathrm{w} / \mathrm{v}), 2 \%(\mathrm{w} / \mathrm{v}), 3 \%(\mathrm{w} / \mathrm{v}), 5 \%(\mathrm{w} / \mathrm{v})$, and $7 \%$ $(\mathrm{w} / \mathrm{v})$ clay in wax matrix, respectively, sprayed on crucibles.

Efficacy of the unique formulation as a sunburn protectant applied to apples. 'Jonagold', 'Cameo', and 'Fuji' apples sprayed with the unique formulation, in three commercial orchards, showed significantly less sunburn browning than the untreated controls (i.e., apples sprayed with water only each time the formulation was sprayed) (Table 2).

The incidence of sunburn necrosis was much lower in all three trials during 1999 (Table 2) as compared with previous years (Table 1). Sunburn necrosis in apples sprayed with the formulation did not differ significantly from controls sprayed with water.

Chlorophyll fluorescence (maximum quantum efficiency of photosystem II) of leaves with a unique formulation applied. Chlorophyll fluorescence was measured in the field to determine whether physiological processes such as the light reactions of photosynthesis are affected by application of the formulation. All $\mathrm{F}_{\mathrm{v}} / \mathrm{F}_{\mathrm{m}}$ values were near 0.8 (Table 3), indicating that maximum quantum efficiency of photosystem II (Fv/Fm) was unaffected on the leaves to which the formulation was applied. The formulation caused no phytotoxicity on either leaves or fruit.

\section{DISCUSSION}

Natural and synthetic waxes that are suitable for human consumption and with melting temperatures that are higher than the melting temperatures of apple cuticular waxes (e.g., carnauba wax, candelilla wax, rice-bran wax, and beeswax) were considered as candidates for the wax emulsion. Carnauba wax, of tropical origin, was selected for several reasons. It contains a mixture of true waxes with long chain fatty acids and long chain esters and is approved for human consumption (Food and Drug Administration, 2009). Carnauba wax is obtained from the leaves of a palm tree known as Copernicia cerifera (Steinle, 1936). This slow-growing Carnauba palm flourishes in the extreme environments of northeastern Brazil because of its protective wax coating (Taube, 1952). Under extreme environments, the tree exudes a wax through the petioles of its fanshaped leaves, preventing dehydration from the equatorial climate and, presumably, photodestruction of essential pigments. Carnaubabased finishing waxes, widely used as a postharvest coating for apples (Kolattukudy, 1984; Kupferman, 1984), are known to spread read- ily and bind to natural waxes of the apple cuticle. Carnauba wax has many industrial applications (Beckett, 1943; Taube, 1952) and is used in waxes to filter out solar radiation that can damage paints on automobiles, for example. Thus, it was reasoned that coating apples with carnauba wax would filter damaging solar radiation.

The transmission studies with quartz crucibles coated with the unique formulation showed that ultraviolet-B and ultraviolet-A transmission were absorbed or filtered by $60 \%$ and $40 \%$, respectively, whereas most radiation in the visible and infrared ranges was transmitted (Fig. 1). This indicates that the formulation mainly absorbs ultraviolet radiation. This finding, coupled with the significant decline in sunburn browning when the formulation was applied to apple trees, suggests that ultraviolet radiation plays an important role in inducing sunburn browning of apples. This needs further investigation, because definitive literature on the effects of ultraviolet-B and ultraviolet-A on sunburn incidence is lacking. As noted in the introduction, several investigators previously suggested a role of ultraviolet radiation in causing sunburn, but experimental evidence is sparse.

The reflectometer (Fig. 2) showed little reflectance below $400 \mathrm{~nm}$ (ultraviolet range) for the unique formulation. Instrument noise was high in measurements below $400 \mathrm{~nm}$, but reflectance in the ultraviolet range did not appear to be significant. The reflectometer used for these studies has a range of 305 to $1100 \mathrm{~nm}$ and detected the most reflectance between 450 and $950 \mathrm{~nm}$. These studies showed that increasing the concentration of clay in the formulation increased reflectance in the visible and near-infrared ranges.

Glenn et al. (2002) used a reflectometer from the same manufacturer except that its detection range was from 195 to $400 \mathrm{~nm}$. They compared reflectance in the ultraviolet range after two and four applications of titanium dioxide and of Surround WP, a white kaolinbased product. They reported substantial reflectance from Surround WP in the range from 320 to $400 \mathrm{~nm}$ (ultraviolet-A) but very little below $310 \mathrm{~nm}$. This indicates that Surround WP reflects mostly ultraviolet-A. Unfortunately, they could not measure reflectance in the visible and infrared regions where one would expect the most reflection from a white product. They showed that titanium dioxide reflected very little solar radiation below 380 $\mathrm{nm}$. Because their instrument did not measure reflectance in the visible or infrared regions, it is not possible to compare their results with mine.

Chlorophyll fluorescence $\left(\mathrm{F}_{\mathrm{v}} / \mathrm{F}_{\mathrm{m}}\right)$ was used to detect any changes in the maximum quantum efficiency of photosystem II of leaves to which the formulation had been applied. Because $\approx 84 \%$ of the incident quanta are absorbed, on average, by a leaf, values for $\mathrm{Fv} / \mathrm{Fm}$ of $\approx 0.8$ indicate healthy leaves with near maximal electron transport. All experimental values in Table 3 were near 0.8 , so the unique formulation did not affect maximum quantum efficiency of photosystem II in apple leaves. 
Further evidence that the unique formulation has no deleterious effects on photosynthesis, respiration, or transpiration was provided by Lombardini (2003), who placed Mylar chambers over 'Fuji' trees to measure whole canopy net carbon exchange and transpiration rates. Untreated trees were compared with those sprayed with the unique formulation. They repeated the measurements four times during the 2000 season with an open system similar to that described by Whiting and Lang (2001). The formulation was applied 1 or $2 \mathrm{~d}$ before the Mylar chambers were installed each month. No significant differences were observed in gas exchange for the untreated control versus formulation-treated trees. Fruit growth, fruit load, fruit size, and fruit maturity characteristics (background color, firmness, soluble solids, titratable acidity, starch/iodine score) were not modified by applications of the unique formulation (Lombardini, 2003).

Sunscreens for human use have traditionally been divided into organic (chemical) absorbers and inorganic (mineral or physical) blockers on the basis of their mechanism of action (Antoniou et al., 2008). The organic compounds absorb high-intensity ultraviolet rays with excitation to a higher energy state. Excess energy is dissipated by emission of longer wavelength light or relaxation by photochemical processes such as isomerization and heat release. These organic (chemical) absorbers include para-aminobenzoic acid (PABA) and PABA esters, salicylates, cinnamates, and many other aromatic compounds. The inorganic agents (minerals) that protect human skin by reflecting and scattering ultraviolet include titanium dioxide, zinc oxide, and other inorganics. Most current commercial sunscreens or suntan lotions used on human skin today combine chemical ultraviolet-absorbing sunscreens and physical inorganic sunscreens, which reflect ultraviolet, to provide broad-spectrum protection (Moloney et al., 2002).

In a similar fashion, RAYNOX ${ }^{\circledR}$ provides a unique technology for sunburn reduction in fruits, because it is the only commercial sunburn protectant for plants that contains organic chemical-absorbing agents in addition to physical inorganic constituents. Carnauba wax, the principal component of RAYNOX ${ }^{\circledR}$, contains cinnamates (Wang et al., 2001) and therefore absorbs ultraviolet. Cinnamates have maximal absorption in the ultraviolet- $\mathrm{B}$ range and can therefore absorb harmful ultraviolet-B radiation. The organoclay in RAYNOX ${ }^{\circledR}$ is a physical inorganic blocker and acts to block, reflect, and scatter radiation. Consequently, RAYNOX ${ }^{\circledR}$, with both an organic chemical absorber and a physical inorganic blocker, provides broad-spectrum protection to fruits from solar radiation injury, just as do current human sunscreens.

Based on the formulation's favorable efficacy results in 1997 and 1998, a provisional patent application was filed in 1998. FruitGard, LLC licensed the technology from Washington State University Research Foundation and partnered with Pace International, LLC in Seattle, WA, to manufacture and distribute the formu- lation, called RAYNOX ${ }^{\circledR}$, in 2003. A composition and utility patent was issued (Kammereck and Schrader, 2005) to Washington State University. Since 2003 , RAYNOX ${ }^{\circledR}$ has become the leading sunburn protectant for apples in the world.

In contrast to RAYNOX ${ }^{\circledR}$, all other products now commercially available for apple sunburn protection are particle films derived from inorganic sources. Surround WP ${ }^{\mathrm{TM}}$ and Cocoon $^{\mathrm{TM}}$ are kaolin (hydrated aluminum silicate), Invelop ${ }^{\mathrm{TM}}$ is talc (hydrated magnesium silicate), and Purshade, Diffusion, and Eclipse $^{\mathrm{TM}}$ are calcium carbonate products. The particle films are white and block, reflect, or scatter solar radiation. They do not contain wax or other ultraviolet-absorbing organics and are not lipophilic emulsions. Because the particle films are generally insoluble in water, they are suspended in water and require constant agitation to prevent the suspension from settling in the sprayer tank.

Steiman et al. (2007) reported that kaolin decreases transmission of ultraviolet-B when sprayed on glass slides. However, it is well established that impurities in standard glass slides effectively block transmission of ultraviolet-B (Duarte et al., 2009; Tuchinda et al., 2006). Moreover, one would not expect kaolin clay to transmit ultraviolet-B. Instead, kaolin would be expected to reflect, block, or scatter radiation.

In general, the inorganic particle film products have proven difficult to remove from fruit as they pass over the packing line. Some users report irritation to nasal passages of orchard workers by the particle films. The particle films also tend to attract mites that prefer a dusty environment. Heavy applications of particle films may also interfere with good color development of apples. None of these problems has been associated with the unique, wax-based technology described in this article.

In summary, the unique formulation 1) significantly decreases sunburn throughout the season; 2) contains only food-quality ingredients approved for human consumption; 3 ) is safe and non-irritating to workers in the orchard; 4) creates a porous film that does not interfere with gas exchange of the leaves or fruits; 5) is formulated to spread and create a uniform film; 6) creates a film on fruit that will withstand rain and overhead evaporative cooling; 7) creates a transparent film on the fruit that allows excellent color development and permits color picking of mature apples; 8) creates a film that is not visible at harvest and does not need removal at packing time; 9) is friendly to the environment with no residues left in dump tanks for disposal; and 10) is less expensive than existing technologies such as shadecloths, overhead evaporative cooling, or bagging of individual fruit.

\section{Literature Cited}

Adegoroye, A.S. and P.A. Joliffe. 1983. Initiation and control of sunscald injury of tomato fruit. J. Amer. Soc. Hort. Sci. 108:23-28.

Antoniou, C., M.G. Kosmadaki, A.J. Stratigos, and A.D. Katsambas. 2008. Sunscreens-What's important to know. European Acad. Dermatol. Venereol. 22:1110-1119.

Barber, H.N. and P.J.H. Sharpe. 1971. Genetics and physiology of sunscald of fruits. Agr. Meteorol. 8:175-191.

Beckett, G. 1943. Carnauba wax in United StatesBrazilian foreign trade. Econ. Geogr. 19:428-430.

Duarte, I., A. Rotter, A. Malvestiti, and M. Silva 2009. The role of glass as a barrier against the transmission of ultraviolet radiation: An experimental study. Photodermatol. Photoimmunol. Photomed. 25:181-184.

Food and Drug Administration. 2009. Code of Federal Regulations Title 21, Volume 3. Subchapter B-Food for human consumption. Part 184-Direct food substances affirmed as generally recognized as safe.

Gindaba, J. and S.J.E. Wand. 2005. Comparative effects of evaporative cooling, kaolin particle film and shade net on the control of sunburn and fruit quality in apples. HortScience 40:592-596.

Gindaba, J. and S.J.E. Wand. 2008. Comparison of climate ameliorating measures to control sunburn on 'Fuji' apples. Acta Hort. 772:59-64.

Glenn, D.M., E. Prado, A. Erez, J. McFerson, and G.J. Puterka. 2002. A reflective, processedkaolin particle film affects fruit temperature, radiation reflection, and solar injury in apple. J. Amer. Soc. Hort. Sci. 127:188-193.

Kammereck, R. and L.E. Schrader. 2005. Use of clay and lipid formulations to protect horticultural crops from sunburn damage and insect damage. U.S. Patent No. 6,857,224 (filed 26 Oct. 1999).

Kolattukudy, P.E. 1984. Natural waxes on fruits. Post Harvest Pomol. Nwsl. 2:3-7. <http://postharvest. tfrec.wsu.edu/pgDisplay.php?article $=\mathrm{N} 2 \mathrm{I} 2 \mathrm{~A}>$.

Kossuth, S.V. and R.H. Biggs. 1978. Sunburned blueberries. Proc. Fla. State Hort. Soc. 91:173175.

Kupferman, E. 1984. Waxing Red Delicious. Post Harvest Pomol. Nwsl. 2:8-15. <http://postharvest. tfrec.wsu.edu/pgDisplay.php?article=N2I2B $>$.

Lipton, W.J. and J.J. O'Grady. 1980. Solar injury of 'Crenshaw' muskmelons: The influence of ultraviolet radiation and of high tissue temperatures. Agr. Meteorol. 22:235-247.

Lombardini, L. 2003. Study of whole-canopy and leaf gas exchange, water relations, chlorophyll fluorescence to understand the effects of cultural practices on growth and productive capacity of apple trees. Washington Tree Fruit Research Commission, Final report, Project \# AH-01-87. <http:// jenny.tfrec.wsu.edu/wtfrc/PDFfinalReports/ 2003FinalReports/AppleHortPath/Lombardini. pdf $>$.

Malitson, I.H. 1965. Interspecimen comparison of the refractive index of fused silica. J. Opt. Soc. Amer. 55:1205-1209.

Moloney, F.J., S. Collins, and G.M. Murphy. 2002. Sunscreens. Safety, efficacy and appropriate use. Amer. J. Clin. Dermatol. 3:185-191.

Parchomchuk, P. and M. Meheriuk. 1996. Orchard cooling with pulsed overtree irrigation to prevent solar injury and improve fruit quality of 'Jonagold' apples. HortScience 31:802-804.

Rabinowitch, H.D., B. Ben-David, and M. Friedmann. 1986. Light is essential for sunscald induction in cucumber and pepper fruits, whereas heat conditioning provides protection. Sci. Hort. 29:21-29.

Rabinowitch, H.D., M. Friedmann, and B. BenDavid. 1983. Sunscald damage in attached and detached pepper and cucumber fruits at various stages of maturity. Sci. Hort. 19:9-18.

Rabinowitch, H.D., N. Kedar, and P. Budowski. 1974. Induction of sunscald damage in tomatoes under natural and controlled conditions. Sci. Hort. 2:265-272. 
Racskó, J., Z. Szabó, and J. Nyéki. 2005. Importance of the supraoptimal radiance supply and sunburn effects on apple fruit quality. Acta Biologica Szegediensis 49:111-114.

Renquist, A.R., H.G. Hughes, and M.K. Rogoyski. 1987. Solar injury of raspberry fruit. HortScience 22:396-397.

Renquist, A.R., H.G. Hughes, and M.K. Rogoyski. 1989. Combined high temperature and ultraviolet radiation injury of red raspberry fruit. HortScience 24:597-599.

Schrader, L., J. Sun, J. Zhang, J.-H. Seo, L. Jedlow, and D. Felicetti. 2004. Fruit skin disorders. Proc. Wash. Tree Fruit Postharvest Conf. $<$ http:// www.tfrec.wsu.edu/pdfs/p412.pdf $>$.

Schrader, L.E., J. Zhang, and W.K. Duplaga. 2001. Two types of sunburn in apple caused by high fruit surface (peel) temperature. Plant Health Prog. doi. 10.1094/PHP-2001-1004-01-RS. $<$ http://www.plantmanagementnetwork.org/pub/ $\mathrm{php} / \mathrm{research} /$ sunburn/>.
Schrader, L.E., J. Zhang, and J. Sun. 2003. Environmental stresses that cause sunburn of apple. Acta Hort. 618:397-405.

Serr, E.F. and J.H. Foott. 1963. Effects of whitewash cover sprays on Persian walnuts in California. Proc. Amer. Soc. Hort. Sci. 82: 243-249.

Sibbett, G.S., W.C. Micke, F.G. Mitchell, G Mayer, and J.T. Yeager. 1991. Effect of a topically applied whitener on sun damage to Granny Smith apples. Calif. Agr. 45:9-10.

Steiman, S.R., H.C. Bittenbender, and T.W. Idol. 2007. Analysis of kaolin particle film use and its application on coffee. HortScience 42:16051608.

Steinle, J.V. 1936. Carnauba wax. An expedition to its source. Ind. Eng. Chem. 28:1004-1008. <http:// dx.doi.org/10.1021/ie50321a003>.

Steel, R.G.D. and J.H. Torrie. 1960. Principles and procedures of statistics. McGraw-Hill Co., New York, NY.
Taube, E. 1952. Carnauba wax: Product of a Brazilian palm. Econ. Bot. 6:379-401.

Tuchinda, C., S. Srivannaboon, and H.W. Lim. 2006. Photoprotection by window glass, automobile glass, and sunglasses. J. Amer. Acad. Dermatol. 54:845-854.

Wang, L., S. Ando, Y. Ishida, H. Ohtani, S. Tsuge, and T. Nakayama. 2001. Quantitative and discriminative analysis of carnauba waxes by reactive pyrolysis-GC in the presence of organic alkali using a vertical microfurnace pyrolyzer. J. Anal. Appl. Pyrolysis 58-59:525-537.

Whiting, M.D. and G.A. Lang. 2001. Canopy architecture and cuvette flow patterns influence whole-canopy net $\mathrm{CO}_{2}$ exchange and temperature in sweet cherry. HortScience 36 : 691-698.

Yuri, J.A., C. Torres, R. Bastias, and A. Neira. 2000. Golpe de sol en manzanas. II. Factores inductores y respuestas bioquimicas. Agrociencia 16:23-32 [abstr. in English]. 